\title{
SIMULATION MODEL FOR JOB SHOP PRODUCTION PROCESS IMPROVEMENT IN MACHINE PARTS MANUFACTURING
}

\author{
Supsomboon, S. \& Vajasuvimon, A. \\ The Sirindhorn International Thai-German Graduate School of Engineering, \\ King Mongkut's University of Technology North Bangkok (KMUTNB), Bangkok, Thailand \\ E-Mail: srisawat.s@tggs.kmutnb.ac.th ("Corresponding author)
}

\begin{abstract}
Job shop production system is characterized by manufacturing feature with low volume and high variety of product designs. It is a process with high flexibility which produces a wide variety of products in low quantities and high divergence. Generally, a job shop production line follows sequence of orders with specific process flow for each particular job. In each work station, special skills of workers are required to perform explicit tasks. Due to these distinctive process characteristics, effective production planning is crucial for job shop manufacturing process. Ineffective production planning may cause several types of waste in production line. This study proposed simulation modeling for job shop production process in machine parts manufacturing. Simulation models present the great benefits to assist in performance improving, problems solving, including a great help in decision making. The experimental results of the study showed that group technology, plant layout, job enlargement, and capacity expansion accomplished the definite value in reducing operating cost and increasing average worker utilization, thereby increasing the efficiency of the system.

(Received in November 2015, accepted in May 2016. This paper was with the authors 1 month for 1 revision.)
\end{abstract}

Key Words: Job Shop Process, Process Improvement, Simulation, Layout, Capacity, Job Enlargement

\section{INTRODUCTION}

\subsection{Problem statement}

In manufacturing industry, an effective production system is crucial. Many times, many companies face production planning problem due to the complication of the production process. This paper proposed production improvement strategies based on principles of production management to increase efficiency of job shop production process in machine parts manufacturing: a case study of fishing net company. Simulation modeling was used in this study to simulate real current process and to compare this current process with the proposed alternative strategies. To evaluate alternative strategies, statistical analysis obtained by the simulation program was used to investigate the results in order to search for the potential improvements which were utilization increasing, waiting or idle time reduction, throughput rate increasing, and operating cost reduction.

Job shop production system is characterized by manufacturing feature with low volume and high variety of product designs. It is a process with high flexibility which produces a wide variety of products in low quantities and high divergence. It is a flexible flow rather than a line flow. Job shop production line generally follows sequence of orders with specific process flow for each particular job. In each work station, special skills of workers are required to perform explicit tasks. Because of such distinctive process characteristics, effective production planning is necessary. Ineffective production plan may cause various wastes such as waiting and idle time in production line, low utilization, and work in process inventory. This paper proposed a case study of job shop production process improvement for machine part manufacturing: a case study of a fishing net company. To present alternative 
strategies, principles of the production management such as plant layout, group technology, job enlargement, and capacity expansion were taken into account.

\subsection{Literature review}

In the late 1950s and 1960s, simulation softwares were very expensive and used only in large companies due to their high investment cost, Maria. Nowadays, computer simulation softwares are widely used in industrial factory because they can be used to evaluate performance of a system under various conditions over long periods of time before implementing changes in the real-world system [1].

In automotive industry, simulation tools were used to design and improve assembly line to increasing productivity, Ülgen and Upendram [2]. They were used to identify bottleneck in assembly process to improve production performance of the system by examining the result of model through the set of statistical analysis in simulation software, Trakultongchai et al. [3]. In part of production planning, Kadar et al. [4] showed the potential of using simulation model in supporting production planning and scheduling. They built a simulation model which constitutes a coherent part of Digital Factory solution. The model was connected to an integrated production planner and job-shop scheduler system. Finally, the results of their experiments could achieve the objectives by using simulation model.

In addition, simulation tool was able to use to compare performance of the proposed models in term of utilization, characteristics of work in process WIP, and ability to meet due date. Technomatix Plant Simulation software was applied as the simulation tool to simulate the comparison of two different production models in research of Stankovic et al. [5]. They focused on the solution of the resizing problem for the actual heavy machining production system. To solve the problem, they applied the shift bottleneck heuristic method for job shop system on the model to optimize the production system through the investigation of bottleneck machines. Flynn and Jacobs [6] used simulation model to compare group technology with traditional and actual job shop manufacturings. The group technology shops presented greater performance in terms of average set-up time and average move time. The traditional job shops had greater performance in variable concerned with queue. Besides, the simulation tools were applied with optimization method to solve the real-world scheduling problem, such as modified shifting bottleneck heuristic, Mason et al. [7], tabu search algorithm and etc. Many research presented the great benefits of the simulation tools to assist in performance improving, problems solving, including a great help in decision making.

Plant layout is one of essential factors for production process because it has a significant effect on the cost and efficiency of operation. One literature in this field, the cellular layout (CL), was frequently compared to the process layout or the traditional functional layout (FL). In the FL, the arrangement of facilities were grouped together according to their functions while CL was the arrangement of a facility so that equipment used to make similar parts or families of parts was grouped together, Anil Kumar and Suresh [8]. Nik Mohamed et al. [9] studied of a steel fabrication works production line in a particular company. The current production layout has to be improved due to the higher demands. They minimized material handling cost, improve flexibility for operation, utilize the available area and minimize overall production time by improving the current layout.

Job design was another essential factor in manufacturing process. The objective of job design was to design jobs which allow people to perform tasks in a safe, efficient, and economical manner which facilitate the realization of various organizational goals such as profit and productivity. Job enlargement could reduce absenteeism and turnovers, and it could reduce monotony and can increase satisfaction of workers, thereby increasing productivity and performance of employees, Saleem et al. [10]. Chakravarty and Shtub [11] showed an optimal job design with respect to the system response time. They also proposed an analytical 
model to achieve such a design. The model suggested that when a new system was considered, an optimal job design is compulsory. Job enlargement can reduce turnovers, absenteeism, and number of repetitions per period, thereby increasing the productivity.

Ho [12] studied staged improvement of delivery-orientated production plan using proposes a system dynamics (SD) model was study. A practical problem in the study was a dynamic approach adjusting enterprise's policy for conforming customers' needs. A dynamic approach for conforming the customers' satisfactions was constructed. Huang et al. [13] developed an improved genetic algorithm for job-shop scheduling problem with process sequence flexibility. Haider et.al [14] proposed an iterative system improvement strategy to explore the potential of tool room. The essence of the proposed system improvement strategy was Lean concepts and methodologies. The results showed that WIP had been reduced as well as tardiness, and production volumes had improved. They concluded that this approach could be used to eliminate wastes, improve process, and prevent defect.

The objectives of this study were to increase the utilization or to decrease the idle time in the system, and to increase the production rate with the lowest costs in job shop production system for machine parts manufacturing. To achieve these objectives, simulation models for job shop production were created.

\section{RESEARCH METHODS}

The great mission of this machinery production department was to produce parts of fishing net machines to support the fishing net production line in the main factory. Another mission was to produce machine parts for other customers outside the company. Most of the time, the company could not deliver products to customers in time due to the delay of the production schedule. The machinery production process composed of 2 main units. They are Computer Numerical Control (CNC) unit and conventional machine unit (manually operated machines). In the study, the conventional machine unit has been taken into account because it created much wastes in the system. The conventional machine unit consisted of 16 main workstations and 11 workers. Customers ordered variety of products with high divergence and uncertain demand. Although working schedule has been designed, but many times it was violated due to waiting in line and thus product could not be finished in time. In the process, there were waiting and idle times of machines as well as workers which caused low utilization. Management team has thought about having robots to dilute the problem. After the observation of the process, we suggested supervisors that they should put effort to reduce waste in the system by applying lean manufacturing or production management first because installation of new robots requires higher investment cost. The main problem in their production process was the low utilization of machine due to idle time and waiting in line. Therefore, production improvement was needed in order to smooth the flow. Simulation method was introduced to study the production system. It was also used to verify possible alternatives. The simulation run results showed that the process could be improved by increasing utilization of resources, reducing waiting or idle time, and increasing production rate with lower operating cost. The steps of improving production process by using simulation method are described below.

\subsection{Process characterization and data collection}

Sets of data for model setup such as process layout, desire throughput rate, cycle time, work schedule, flow chart, and flow process chart were required. These necessary data were collected from the production process in one month period. The production process of the plant was divided into two units as mentioned earlier: CNC machine and conventional machine units. This study focused only on the conventional machine unit. The conventional 
machine unit consisted of 16 main workstations and 11 workers. Each worker had different responsibility to operate each particular machine. The layout of this production line is illustrated in Fig. 1. The gray area is the area of conventional machine units.

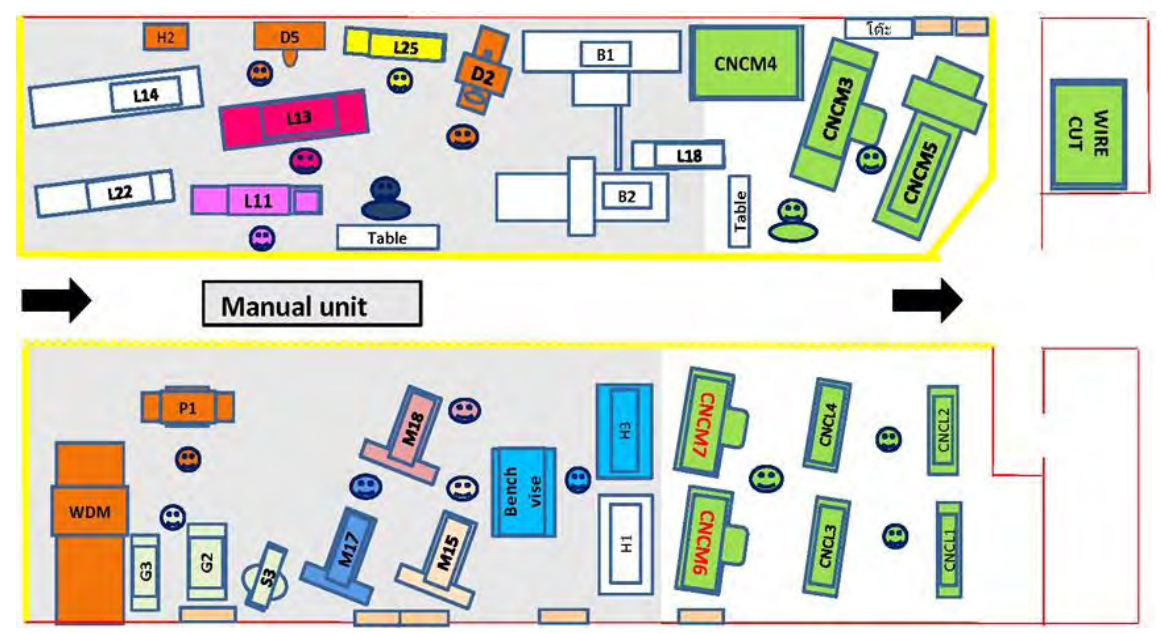

Figure 1: Layout of conventional machine unit.

The conventional machine unit had various types of machine. Table I presents function of each workstation and responsibility of workers, including workstations description.

Table I: Workstations responsibility.

\begin{tabular}{|c|c|c|}
\hline Worker & Workstation & Workstation's responsibility \\
\hline A & M15 & Vertical milling machine \\
\hline B & M17 & Vertical milling machine \\
\hline $\mathrm{C}$ & M18 & Vertical milling machine \\
\hline $\mathrm{D}$ & $\mathrm{L} 25$ & General lathe machine \\
\hline $\mathrm{E}$ & L11 & Heavy duty lathe machine \\
\hline $\mathrm{F}$ & L13 & Heavy duty lathe machine \\
\hline $\mathrm{G}$ & $\mathrm{D} 2$ & Radius drilling machine \\
\hline $\mathrm{H}$ & $\begin{array}{l}\text { D5 } \\
\text { H2 }\end{array}$ & $\begin{array}{l}\text { Upright drilling machine } \\
\text { Hobbing machine }\end{array}$ \\
\hline I & $\begin{array}{c}\text { P1 } \\
\text { WDM }\end{array}$ & $\begin{array}{l}\text { Press machine } \\
\text { Welding }\end{array}$ \\
\hline $\mathrm{J}$ & $\begin{array}{c}\text { Tap and F } \\
\text { H3 }\end{array}$ & $\begin{array}{l}\text { Tapping and finishing } \\
\text { Hobbing machine }\end{array}$ \\
\hline K & $\begin{array}{l}\text { G2 } \\
\text { G3 } \\
\text { S3 }\end{array}$ & $\begin{array}{l}\text { Surface grinding machine } \\
\text { Cylinder grinding machine } \\
\text { Slotting machine }\end{array}$ \\
\hline
\end{tabular}

Total number of customer orders in a period of one month observation was 568 orders. Most of product items were diverse and required different process flow in various quantities. All 568 orders were classified into groups by its process flow. Most items of product could be grouped into 46 groups. Only 86 items could not be grouped. After raw data and information were collected according to the above group classification, raw data was converted to be input parameters of simulation model. Regular working time is 8 hours, from 8.00 a.m. to 5 p.m. with an hour lunch break for six days a week. Therefore, regular working time is 8 hours a day and 26 days a month. Total available time for regular hour is then 12,480 minutes per month observation. Table II presents information of available time for overtime and actual overtime of each worker of a month. The supervisor designed overtime to be only for 4 options: 19.00, 20.00, 21.00, and 23.00 for some reasons. 
Table II: Available time for normal time and for overtime of workers in one month.

\begin{tabular}{|c|c|c|c|c|c|c|c|c|c|c|c|c|}
\hline \multirow[t]{2}{*}{ Machine } & \multirow[t]{2}{*}{ Worker } & \multirow{2}{*}{$\begin{array}{c}\begin{array}{c}\text { Regular } \\
\text { working } \\
\text { time } \\
(\mathrm{min})\end{array} \\
8.00-17.00\end{array}$} & \multicolumn{4}{|c|}{$\begin{array}{l}\text { Available Overtime } \\
\text { (min) }\end{array}$} & \multirow{2}{*}{$\begin{array}{c}\text { Total } \\
\text { Available } \\
\text { time } \\
\text { (min) }\end{array}$} & \multicolumn{4}{|c|}{ Actual Overtime (min) } & \multirow{2}{*}{$\begin{array}{c}\text { Total } \\
\text { Over } \\
\text { time } \\
\text { (min) }\end{array}$} \\
\hline & & & 19.00 & 20.00 & 21.00 & 23.00 & & 19.00 & 20.00 & 21.00 & 23.00 & \\
\hline M15 & Worker A & 4320 & - & 3150 & - & - & 7470 & - & 750 & - & - & 750 \\
\hline M17 & Worker B & 12480 & - & - & - & - & 12480 & - & - & - & - & 0 \\
\hline M18 & Worker C & 4800 & - & - & 10350 & - & 15150 & - & - & 3150 & - & 3150 \\
\hline L25 & Worker D & 4800 & 8550 & - & - & - & 13350 & 1350 & - & - & - & 1350 \\
\hline L11 & Worker E & 8160 & - & - & 4140 & 810 & 13110 & - & - & 1260 & 330 & 1590 \\
\hline L13 & Worker F & 5760 & - & - & 5520 & - & 11280 & - & - & 1680 & - & 1680 \\
\hline D2 & Worker G & 10080 & - & - & 3450 & - & 13530 & - & - & 1050 & - & 1050 \\
\hline $\mathrm{D} 5+\mathrm{H} 2$ & Worker H & 8160 & 57 & - & 2760 & - & 11490 & 90 & - & 840 & - & 930 \\
\hline $\mathrm{P} 1+\mathrm{WDM}$ & Worker I & 5760 & - & 8190 & - & - & 13950 & - & 1950 & - & - & 1950 \\
\hline$\frac{\mathrm{H} 3}{\mathrm{TAP}+\mathrm{F}}$ & Worker J & 1920 & - & 5670 & 8280 & - & 15870 & & 1350 & 2520 & - & 3870 \\
\hline $\mathrm{G} 2+\mathrm{G} 3+\mathrm{S} 3$ & Worker K & 12480 & - & - & - & - & 12480 & - & - & - & - & 0 \\
\hline Total & 11 & 78720 & 9120 & 17010 & 34500 & 810 & 140160 & 1440 & 4050 & 10500 & 330 & 16320 \\
\hline
\end{tabular}

Table III shows the conclusion of Machine and worker utilizations of the current system. Worker $\mathrm{A}$ to worker $\mathrm{G}$ is assigned to operate one machine. Worker $\mathrm{H}$ operates 2 machines (D5, H2). Worker I operates 2 machines (P1, WDM). Worker J operates 2 machines (TAP+F, $\mathrm{H} 3$ ). Worker K operates 3 machines (G2, G3, and S3). Once a worker operates more than one machine, the machine utilization is relatively low as shown in the table below.

Table III: Machine utilization and worker utilization of the current system.

\begin{tabular}{|c|c|c|c|c|c|c|c|}
\hline Machine & $\begin{array}{c}\text { Available } \\
\text { time (min) }\end{array}$ & $\begin{array}{c}\text { Working } \\
\text { time }(\mathrm{min})\end{array}$ & $\begin{array}{c}\text { Machine } \\
\text { utilization }(\%)\end{array}$ & Worker & $\begin{array}{c}\text { Available } \\
\text { time (min) }\end{array}$ & $\begin{array}{c}\text { Working } \\
\text { time (min) }\end{array}$ & $\begin{array}{c}\text { Worker } \\
\text { utilization }(\%)\end{array}$ \\
\hline M15 & 13230 & 6850 & 51.78 & Worker A & 7470 & 6850 & 91.70 \\
\hline M17 & 12480 & 12110 & 97.04 & Worker B & 12480 & 12110 & 97.04 \\
\hline M18 & 15150 & 13898 & 91.74 & Worker C & 15150 & 13898 & 91.74 \\
\hline L25 & 13350 & 13350 & 100.00 & Worker D & 13350 & 13350 & 100.00 \\
\hline L11 & 13110 & 12975 & 98.97 & Worker E & 13110 & 12975 & 98.97 \\
\hline L13 & 11040 & 10250 & 92.84 & Worker F & 11040 & 10250 & 92.84 \\
\hline D2 & 13530 & 12485 & 92.28 & Worker G & 13530 & 12485 & 92.28 \\
\hline D5 & 10210 & 7700 & 75.42 & \multirow{2}{*}{ Worker H } & \multirow{2}{*}{10210} & \multirow{2}{*}{8470} & \multirow{2}{*}{82.96} \\
\hline $\mathrm{H} 2$ & 10210 & 770 & 7.54 & & & & \\
\hline $\mathrm{P} 1$ & 13950 & 6655 & 47.71 & \multirow{2}{*}{ Worker I } & \multirow{2}{*}{13950} & \multirow{2}{*}{13010} & \multirow{2}{*}{93.26} \\
\hline WDM & 13950 & 6355 & 45.56 & & & & \\
\hline $\mathrm{TAP}+\mathrm{F}$ & 15870 & 14254 & 89.82 & \multirow{2}{*}{ Worker J } & \multirow{2}{*}{15870} & \multirow{2}{*}{15087} & \multirow{2}{*}{95.07} \\
\hline H3 & 15870 & 2130 & 13.42 & & & & \\
\hline G2 & 12480 & 2475 & 19.83 & \multirow{3}{*}{ Worker K } & \multirow{3}{*}{12480} & \multirow{3}{*}{8975} & \multirow{3}{*}{71.92} \\
\hline G3 & 12480 & 1440 & 11.54 & & & & \\
\hline S3 & 12480 & 5180 & 41.51 & & & & \\
\hline Average & 13086.88 & 8054.813 & 61.06 & Average & 12603.64 & 11587.27 & 91.62 \\
\hline
\end{tabular}

\subsection{Simulation setup}

Tecnomatix Plant Simulation software version 10 licensed by Siemens was used to create simulation models. Basic assumptions which have been made in the simulation are described below. 
Assumptions:

1. Each job had a specific process flow.

2. Each machine could be operated by one worker at a time for any tasks.

3. An operation on any job could not be performed until previous operation on that job was completed.

4. First-In-First-Out service and jobs were independent.

5. There was no interruption in the shop floor (e.g., no machine breakdown).

6. Transportation times between machines were negligible.

7. Setup time was already included in the processing time of each job.

8. No assembly was involved.

9. Each worker worked for 6 days in a week.

10. Working time of machines and workers followed the schedule.

11. Eight hours of one shift for normal working hours with one hour break time was applied (working beyond normal working hours was considered overtime).

12. A machine required one worker to operate it, and a worker could not operate more than one machine at a time.

\subsection{Model validation}

Model validation is used to statistically proof whether simulation model could represent the real-world system with a given significant level. Statistical validity involves a quantitative comparison between the performance of the actual system and the model at a certain confident interval. If there is no statistically significant difference between the data sets, then the model is considered valid. On the other hand, if there is a statistically significant difference, then the model is not valid. Simulation run results were investigated. Three performance measurements of simulation results; throughout per day, machine utilization, and worker utilization, were examined. Table IV presents an example of worker utilization of the real current system and simulation model.

Table IV: Worker Utilization of the real current system and simulation model.

\begin{tabular}{|c|c|c|}
\hline Worker & $\begin{array}{c}\text { Real current system } \\
(\mathrm{R})(\boldsymbol{\%})\end{array}$ & $\begin{array}{c}\text { Simulation model } \\
(\mathrm{M})(\%)\end{array}$ \\
\hline Worker A & 91.70 & 80.63 \\
\hline Worker B & 97.04 & 91.69 \\
\hline Worker C & 91.74 & 99.93 \\
\hline Worker D & 100.00 & 78.72 \\
\hline Worker E & 98.97 & 87.99 \\
\hline Worker F & 92.84 & 89.38 \\
\hline Worker G & 92.28 & 90.65 \\
\hline Worker H & 82.96 & 82.64 \\
\hline Worker I & 93.26 & 89.43 \\
\hline Worker J & 95.07 & 86.69 \\
\hline Worker K & 71.92 & 70.14 \\
\hline Mean & 91.62 & 86.17 \\
\hline STD. & 7.96 & 7.87 \\
\hline
\end{tabular}

The statistical $t$-test was used to validate the results of the actual system and the model under assumption that the population standard deviations were unknown and the amount of sample was less than thirty samples. An example of hypothesis testing for average worker utilization is shown below as well as the calculation of 2 -independent samples $t$-test for the mean of worker utilization. 


$$
\begin{aligned}
& H_{0}: \mu_{R}-\mu_{M}=0 \\
& H_{1}: \mu_{R}-\mu_{M} \neq 0
\end{aligned}
$$

where: $\mu_{R}$ : mean of real current worker utilization,

$\mu_{M}$ : mean of model worker utilization.

The test statistic: $t=\frac{(91.62-86.17)}{\sqrt{\frac{(7.96)^{2}}{11}+\frac{(7.87)^{2}}{11}}}=1.613$

Degree of freedom $(d f)=22-2=20$. Significance level $\alpha=0.05 . P$-value $=0.122>0.05$.

The average of worker utilization in real current system was $91.62 \%$ while the worker utilization of simulation model was $86.17 \%$. The test statistic of 1.61 was between -2.086 and 2.086 while the $p$-value of the $t$-test was 0.122 at 95 percent of confidence interval which was higher than 0.05 . Thus, null hypothesis could not be rejected. There was no statistically significant difference between the real system and the simulation model. It could be concluded that this model was able to use as a representative of the real current system. Three performance measurements which were validated in this process; throughput rate per day, average machine utilization, and worker utilization were tested. The results of statistical $t$-test were presented in Table V.

Table V: Results of hypothesis testing.

\begin{tabular}{|l|c|c|c|}
\hline \multicolumn{1}{|c|}{ Variable } & Actual result & Model result & $\boldsymbol{P}$-value \\
\hline Throughput (pcs) per day & 127 & 123 & 0.866 \\
\hline Machine utilization (\%) & 61.06 & 57.50 & 0.770 \\
\hline Worker utilization (\%) & 91.62 & 86.17 & 0.122 \\
\hline
\end{tabular}

From the above results, $p$-value of each parameter was higher than 0.05 at $95 \%$ of confidence interval. Thus, there was no statistically significant difference between the real current system and simulation model. We could conclude that the simulation model is valid.

\section{PROPOSED ALTERNATIVE STRATEGIES}

The alternative strategies were developed to improve the current system under the objectives of utilization increasing, idle time reduction, and throughput rate increasing with the lowest operation cost of the system. Three possible strategies were proposed in this section.

\subsection{Strategy A: Process layout by group technology and job enlargement}

In real current production process, even though the utilization of worker was only $91.62 \%$, overtime were still required because most workers were assigned to work also in other departments in the plant. This overtime caused higher operating cost. Strategy A considered the way of reducing overtime by using group technology with process layout and job enlargement. Similar workstations which perform similar tasks were grouped. The improvement of process layout was applied at vertical milling machines and heavy duty lathe machines. Fig. 2 shows the layout of heavy duty lathe machines at L11 and L13 workstations before and after modifying process layout. These parallel machines increased the flow of materials and work in process (WIP). Similarly, the layout of vertical milling machines for M17 and M18 workstations were grouped together and operated in parallel to increase utilization and decrease idle time. 


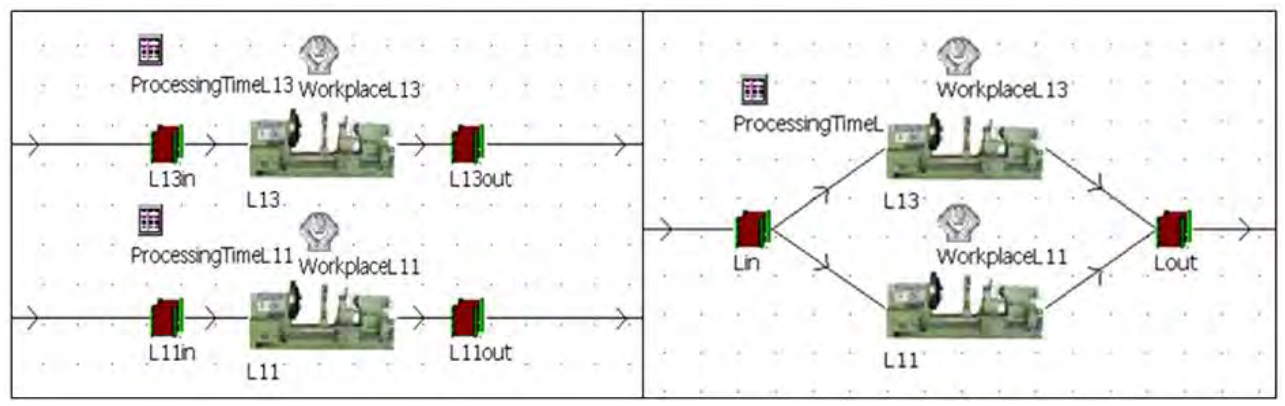

Figure 2: Machine layout of production line: before (left) and after rearrangement (right).

Moreover, job enlargement was applied. Workers were arranged to take responsibility for more than one specific task in this strategy in order to increase the worker utilization. In the experiment, workers who had low utilization were assigned to help those who had high workloads. Fig. 3 shows that a worker whose job was enlarged from three tasks to four tasks. This could reduce overtime of other workers without negative impact to the system.

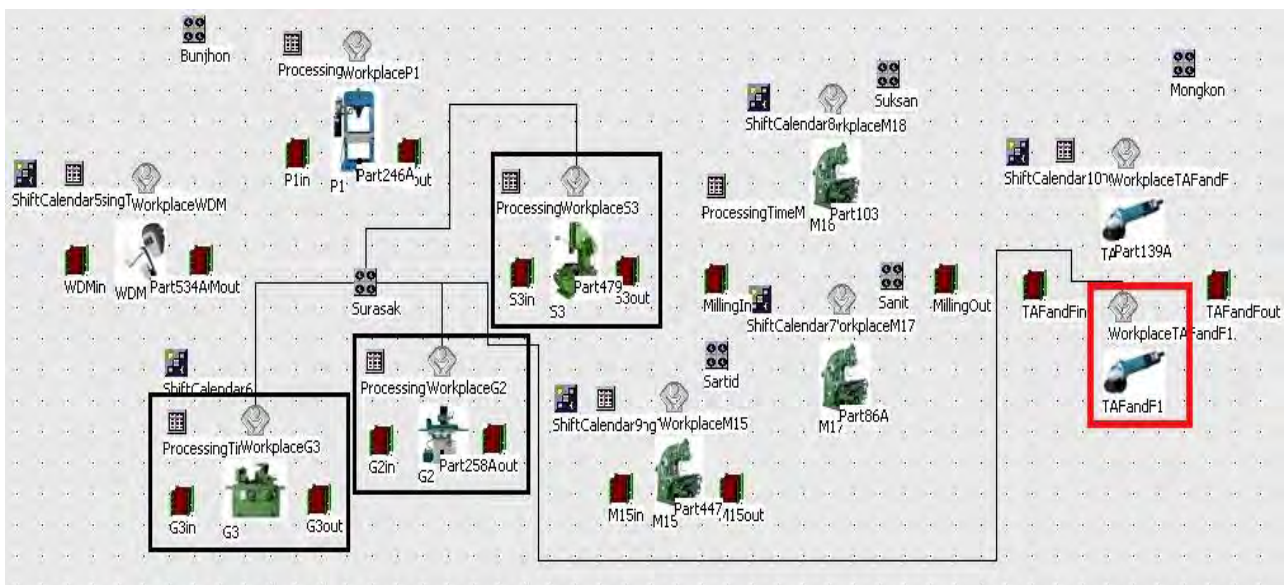

Figure 3: The job enlargement of a worker in production line.

Table VI presents the results of Strategy A. Strategy A could increase machine utilization, increase worker utilization, reduce operating cost, and increase throughput from current system. It could also reduce overtime by increasing time of working in regular hour due to the higher usage of machine after applying group technology and job enlargement.

Table VI: Simulation results of Strategy A: Process layout by group technology and job enlargement.

\begin{tabular}{|l|c|c|c|c|}
\hline \multicolumn{1}{|c|}{ Model } & $\begin{array}{c}\text { Avg. Machine } \\
\text { utilization (\%) }\end{array}$ & $\begin{array}{c}\text { Avg. Worker } \\
\text { utilization (\%) }\end{array}$ & $\begin{array}{c}\text { Operating Cost } \\
\text { (US\$) }\end{array}$ & $\begin{array}{c}\text { Throughout } \\
\text { (pcs) per day }\end{array}$ \\
\hline 1. Current system & 57.50 & 86.17 & 15,918 & 123 \\
\hline 2. Process layout & 58.11 & 89.20 & 15,452 & 125 \\
\hline 3. Job enlargement & 58.23 & 87.22 & 15,755 & 124 \\
\hline $\begin{array}{c}\text { 4. Process layout and Job } \\
\text { enlargement }\end{array}$ & 59.19 & 90.89 & 15,114 & 124 \\
\hline
\end{tabular}

\subsection{Strategy B: Activating idle machines, job enlargement, and additional workers}

In the production plant, there had been some of idle machines which still in good conditions but left idle. Therefore, we considered activating these idle machines and enlarging some of workers' job in this strategy. Pareto Charts shown in Fig. 4 indicated that the general lathe machine (L25) and the heavy duty lathe machine (L11) had highest workload among all other 
machines. Therefore, two idle lathe machines were considered to start working in the process for the purpose of capacity expansion.

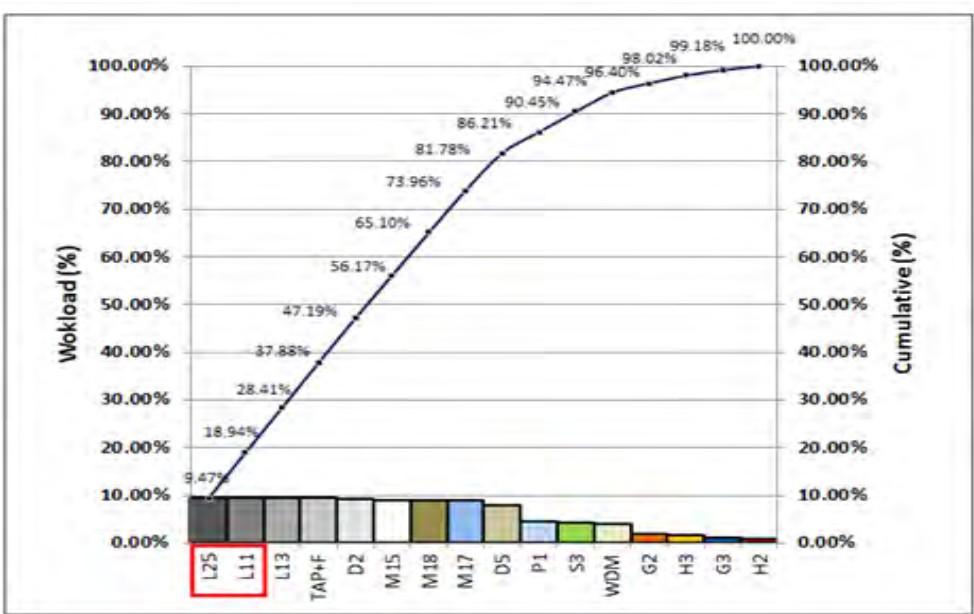

Figure 4: Pareto chart of workload of machines in current production process.

In the experiment, two idle lathe machines which were general lathe machine (L18) and a heavy duty lathe machine (L22) were added into production process. Layout of production line with the two additional machines was shown in Fig. 5. As mentioned earlier, these additional lathe machines had already been installed in the production line but no worker assigned to operate them. Therefore, no additional investment for new machines was needed. (In case that the factory did not have these machines, investment cost had to be taken into account.)

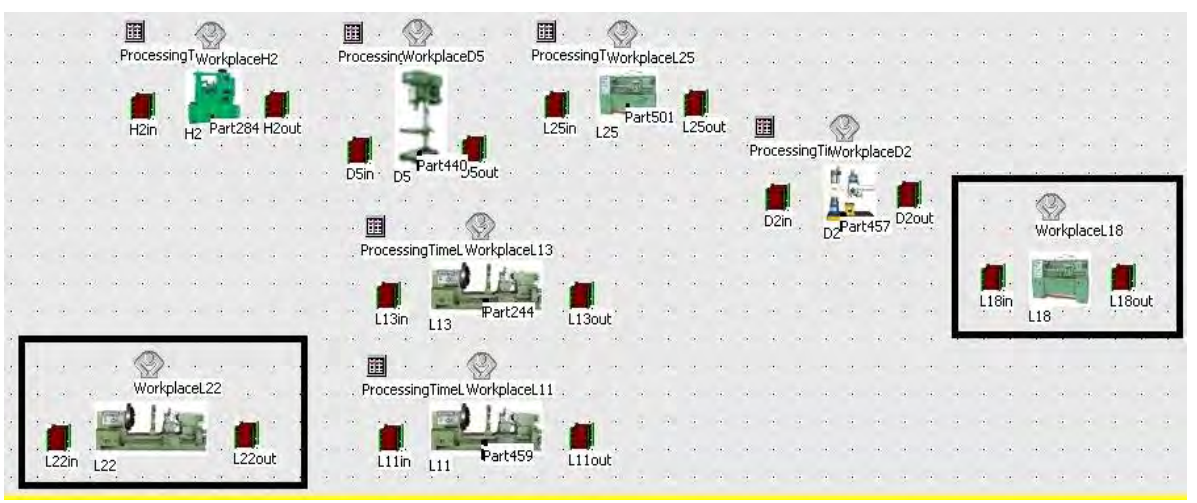

Figure 5: Layout of production line with the two additional lathe machines.

To consider the optimal number of extra workers, relationship between amount of workers and other three related performance measurements were considered. From the analytical results of simulation, the best solution was to add one worker into production line to operate two additional machines rather than two workers. Average utilizations and operating cost are shown in Table VII. Therefore, adding one extra worker was the optimal solution in this strategy.

Table VII: Simulation Analysis of adding extra workers in strategy B.

\begin{tabular}{|l|c|c|c|c|c|}
\hline \multicolumn{1}{|c|}{ Model } & $\begin{array}{c}\text { Number of } \\
\text { workers }\end{array}$ & $\begin{array}{c}\text { Avg. Machine } \\
\text { utilization (\%) }\end{array}$ & $\begin{array}{c}\text { Avg. Worker } \\
\text { utilization (\%) }\end{array}$ & $\begin{array}{c}\text { Operating Cost } \\
\text { (US\$) }\end{array}$ & $\begin{array}{c}\text { Throughout } \\
\text { (pcs) per day }\end{array}$ \\
\hline 1. Current System & 11 & 57.50 & 86.17 & 15,918 & 123 \\
\hline 2. One extra worker & 12 & 66.31 & 99.26 & 14,363 & 150 \\
\hline 3. Two extra workers & 13 & 66.00 & 91.05 & 15,553 & 150 \\
\hline
\end{tabular}




\subsection{Strategy C: Additional workers and 2-shift working system}

Pareto Charts in Fig. 4 also indicates that the capacity of the milling machine (M) and heavy duty machine (L) should also be expanded due to their high workloads. In strategy C, capacity of vertical milling machine and heavy duty lathe machine were considered to be expanded in order to increase capacity of the entire production line. The results of strategy A and B showed that the average worker utilizations were very close to $100 \%$. Since worker capacity was a system constraint, 2-shift working system has been brought in to consideration in this strategy in order to increase throughput with no overtime.

To add of extra workers in production process for both shifts, break-even analysis had been taken into account. The relationship between number of extra workers with operating cost and finish time of production were analyzed. A graph of relationship between number of extra workers and the operating cost in Fig. 6 a shows that adding four extra workers conducted the lowest operating cost. While the graph of relationship between number of extra workers and finish time of production in Fig. $6 \mathrm{~b}$ shows that the trend line was decreased and almost constant at the number of extra workers of 4 as well. As a result, adding four extra workers was the optimal solution. Therefore, the total amount of workers in strategy $\mathrm{C}$ was fifteen workers.

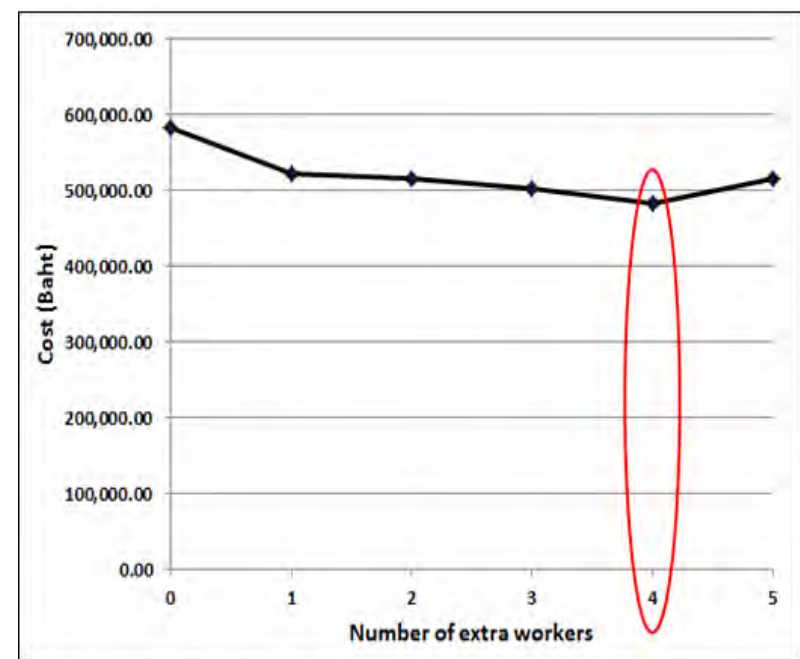

a)

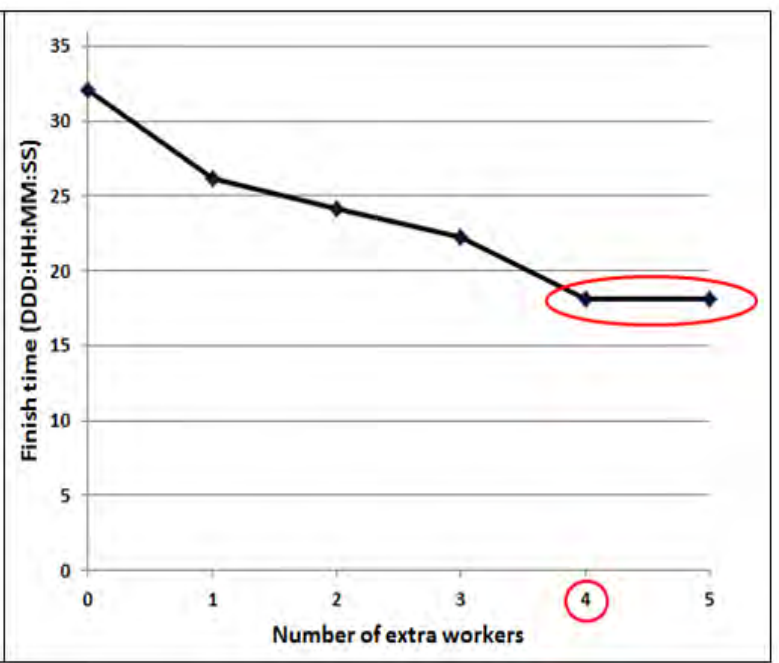

b)

Figure 6: Graph of relationships between: a) number of extra workers and operating cost, and b) number of extra workers and finish time of production.

Additional workers should be trained to have multiple skills and be able to operate the high workload machines. Table VIII presents skills requirement of four extra workers.

Table VIII: Skill requirements for workers in Strategy C.

\begin{tabular}{|l|l|}
\hline Worker & \multicolumn{1}{c|}{ Skill requirements } \\
\hline Worker A & M17 (Vertical milling machine) \\
\hline \multirow{2}{*}{ Extra worker 1 } & Tap and F (Tapping and finishing) \\
\cline { 2 - 2 } & L25 (General lathe machine) \\
\hline \multirow{2}{*}{ Extra worker 2 } & L11 (Heavy duty lathe machine) \\
\cline { 2 - 2 } & D2 (Radius drilling machine) \\
\hline \multirow{2}{*}{ Extra worker 3 } & M18 (Vertical milling machine) \\
\cline { 2 - 2 } & Tap and F (Tapping and finishing) \\
\hline \multirow{2}{*}{ Extra worker 4 } & Tap and F (Tapping and finishing) \\
\cline { 2 - 2 } & D2 (Radius drilling machine) \\
\hline
\end{tabular}




\section{RESULTS AND DISCUSSIONS}

In this section, the best results of experiments from strategy $\mathrm{A}, \mathrm{B}$, and $\mathrm{C}$ were chosen and compared in terms of percentage of average utilization, operating cost, finished time, and throughout per day as shown in Table IX.

Table IX: Comparison of simulation results.

\begin{tabular}{|l|c|c|c|c|c|}
\hline \multicolumn{1}{|c|}{ Model } & $\begin{array}{c}\text { Number of } \\
\text { workers }\end{array}$ & $\begin{array}{c}\text { Avg. Worker } \\
\text { utilization (\%) }\end{array}$ & $\begin{array}{c}\text { Operating } \\
\text { Cost (US\$) }\end{array}$ & $\begin{array}{c}\text { Finish time } \\
\text { (DD:HH:MM:SS) }\end{array}$ & $\begin{array}{c}\text { Throughput } \\
\text { (pcs) per day }\end{array}$ \\
\hline 1. Current System & 11 & 86.17 & 15,918 & $31: 00: 00: 00$ & 123 \\
\hline 2. Strategy A & 11 & 90.89 & 15,114 & $30: 16: 50: 57$ & 124 \\
\hline 3. Strategy B & 12 & 99.26 & 14,363 & $25: 10: 48: 05$ & 150 \\
\hline 4. Strategy C & 15 & 97.79 & 13,794 & $18: 09: 16: 36$ & 208 \\
\hline
\end{tabular}

Worker utilization was focused more than machine utilization because worker capacity was a major constraint of the system since it limited the capacity of the process. Capacity of machines was not a limitation of the system. The average worker utilization of Model A, B and $\mathrm{C}$ were increased from the real current production model. Strategy B shows the highest average worker utilization when comparing with Model A and Model C. The average worker utilization of Model $\mathrm{C}$ was less than the average worker utilization of Model B because the amount of workers in Model $\mathrm{C}$ was higher with two shifts of working. Thus, they had more free time. One of essential performance measurement was production rate of system which was presented in the form of throughput per day. As shown in simulation results, the finished time of strategy $\mathrm{C}$ was less than another models, thus the production rate was the highest among other models. This was because of the expansion of working hours from 1 shift to 2 shifts. Another performance measurement is percentage of idle time in production system. The deductions of workers' idle time of strategies A, B, and C from the real current process were $34.13 \%, 94.65 \%$ and $84.02 \%$, respectively.

\section{CONCLUSIONS AND FUTURE STUDY}

This paper proposed the alternative solutions for production management in order to improve machinery production process in job shop through alternative strategies based on basic principle of operations management. Simulation models showed the great performance to help in making a decision before implementing alternative strategies in real system. From the experiment results, group technology, plant layout, job enlargement, and capacity expansion were able to help reducing operating cost, increasing average worker utilization, as well as increasing throughput.

As a conclusion, the results showed that strategy B performed superior performance prior to other strategies in terms of average worker utilization, while strategy $\mathrm{C}$ was outstanding in terms of operating costs and throughput per day. In case that the company policy was opened for 2-shift working system, strategy $\mathrm{C}$ should be considered for long terms benefit. Otherwise, strategy B was the most preferable. The alternative plan of strategy B can reduce most idle time up to $94.65 \%$. It could be concluded that adding extra machines and job enlargement strategies could decrease idle time in the system. Adding extra workers to high workload machines was one of most interesting alternative which could make significant impact on production improvement. From point of view of company management team, adding extra workers in order to operate the idle machines is also the most practical solutions because machines were not allowed to relayout for some reasons. Therefore, future research plan which include consideration of machine layout should be taken into account. 


\section{ACKNOWLEDGEMENT}

This research was funded by King Mongkut's University of Technology North Bangkok (KMUTNB), Contract Number KMUTNB-GEN-58-54.

\section{REFERENCES}

[1] Maria, A. (1997). Introduction to modeling and simulation, Proceedings of the 1997 Winter Simulation Conference (WSC '97), 7-13, doi:10.1109/WSC.1997.640371

[2] Ülgen, O. M.; Upendram, S. S. (1997). Productivity simulation in the automotive industry, Proceedings of the SCS 1997 Multiconference, 199-204

[3] Trakultongchai, A.; Supsomboon, S.; Limtanyakul, K. (2013). Process simulation and improvement of automotive paint shop, International Journal of Mining, Metallurgy \& Mechanical Engineering (IJMMME), Vol. 1, No. 1, 4 pages (Online)

[4] Kadar, B.; Pfeiffer, A.; Monostori, L. (2004). Discrete event simulation for supporting production planning and scheduling decisions in digital factories, Proceedings of the $37^{\text {th }}$ CIRP International Seminar on Manufacturing Systems, 441-448

[5] Stankovic, I.; Car, Z.; Barisic, B. (2011). Comparative simulations of the heavy machining production system, Engineering Review, Vol. 31, No. 1, 11 pages (Online)

[6] Flynn, B. B.; Jacobs, F. R. (1986). A simulation comparison of group technology with traditional job shop manufacturing, International Journal of Production Research, Vol. 24, No. 5, 11711192, doi: 10.1080/00207548608919795

[7] Mason, S. J.; Fowler, J. W.; Carlyle, W. M. (2002). A modified shifting bottleneck heuristic for minimizing total weighted tardiness in complex job shops, Journal of Scheduling, Vol. 5, No. 3, 247-262, doi: $10.1002 /$ jos. 102

[8] Anil Kumar, S.; Suresh, N. (2009). Production and Operations Management, $2^{\text {nd }}$ ed., New Age International Pvt Ltd. Publishers, New Delhi, 42-46

[9] Nik Mohamed, N. M. Z.; Ab Rashid, M. F. F.; Mohd Rose, A. N.; Ting, W. Y. (2015). Production layout improvement for steel fabrication works, Journal of Industrial and Intelligent Information, Vol. 3, No. 2, 133-137, doi:10.12720/jiii.3.2.133-137

[10] Saleem, S.; Shaheen, W. A.; Saleem, R. (2012). The impact of job enrichment and job enlargement on employee satisfaction keeping employee performance as intervening variable: a correlational study from Pakistan, Kuwait Chapter of Arabian Journal of Business and Management Review, Vol. 1, No. 9, 145-165

[11] Chakravarty, A. K.; Shtub, A. (1988). Modelling the effects of learning and job enlargement on assembly systems with parallel lines, International Journal of Production research, Vol. 26, No. 2, 267-281, doi:10.1080/00207548808947858

[12] Ho, Y.-L. (2015). Staged improvement of delivery-oriented production, International Journal of Simulation Modelling, Vol. 14, No. 1, 17-27, doi:10.2507/IJSIMM14(1)2.272

[13] Huang, X. W.; Zhao, X. Y.; Ma, X. L. (2014). An improved genetic algorithm for job-shop scheduling problem with process sequence flexibility, International Journal of Simulation Modelling, Vol. 13, No. 4, 510-522, doi:10.2507/IJSIMM13(4)CO20

[14] Haider, A.; Mirza, J.; Ahmad, W. (2015). Lean capacity planning for tool room: An iterative system improvement approach, Advances in Production Engineering \& Management, Vol. 10, No. 4, 169-184, doi:10.14743/apem2015.4.200 